InVisible Culture • Issue 33: After Douglas Crimp

\title{
After Douglas Crimp \\ Questionnaire Response: \\ Tara Najd Ahmadi
}

\section{Tara Najd Ahmadi}

Published on: Jan 05, 2022

DOI: https://doi.org/10.47761/494a02f6.e070d256

License: Creative Commons Attribution 4.0 International License (CC-BY 4.0). 


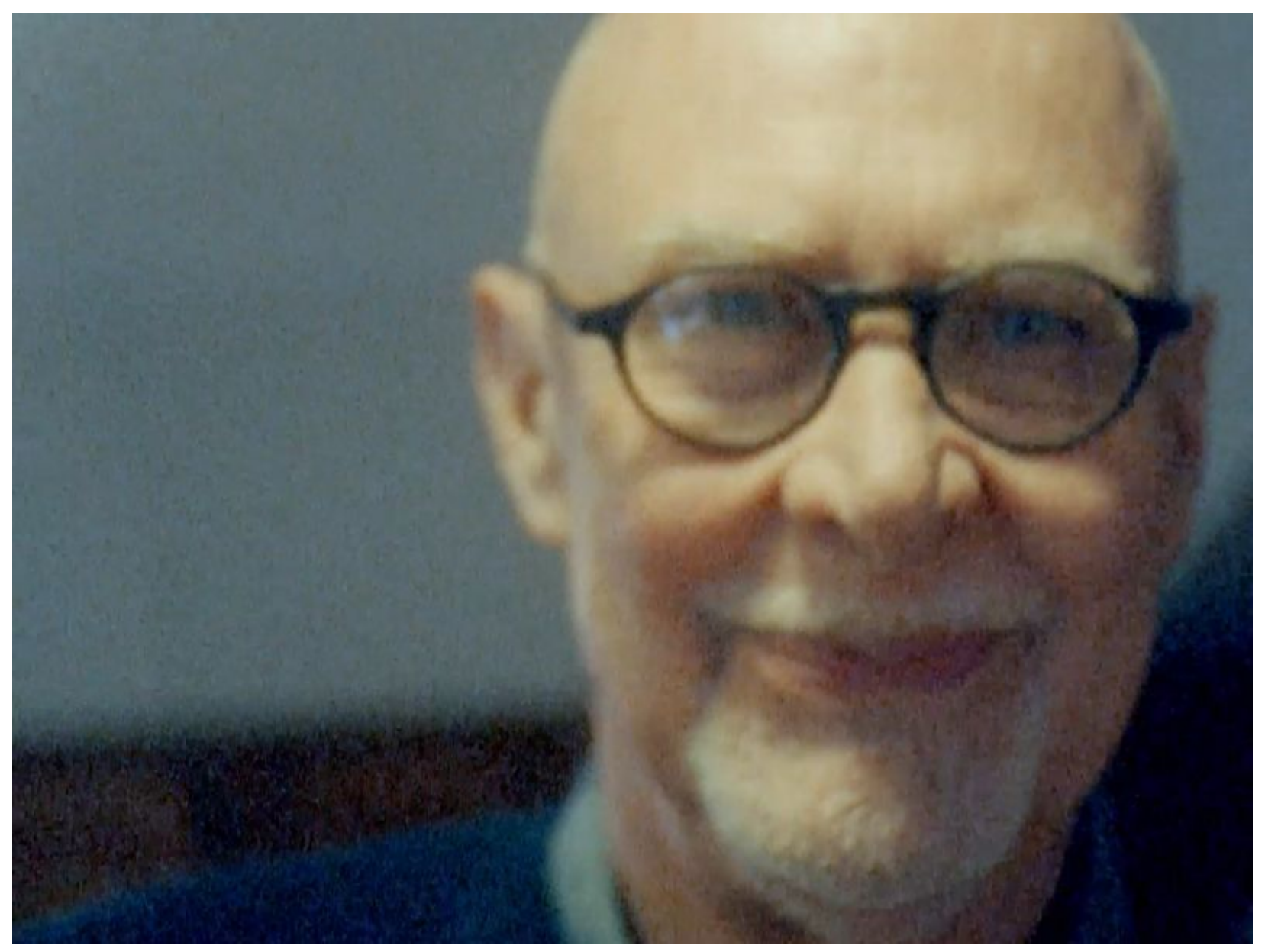

An Art Historian's Recipe is a short film homage to art historian Douglas Crimp (1944-2019). In the 1970s, Crimp and his boyfriend attempted to publish a Moroccan cookbook in New York City, but their project failed and the book was never published. The film's narration consists of excerpts from Crimp's memoir, Before Pictures. The footage is a collage of 16mm films shot between 2017 and 2021. Central to the footage are scenes of Crimp preparing a tagine dish (from his unpublished cookbook) with his students at the University of Rochester.

Directed by: Tara Najd Ahmadi

Voices: Lauren DiGiulio

Amanda Graham

Jurij Meden

Tara Najd Ahmadi 
Edit: Per the artist's request, this film was available for one year after the publication of this issue. For more info on her work, see the artist's website: https://najdahmadi.com/.

Tara Najd Ahmadi is an artist and scholar, based in Vienna.

Click here to return to the other questionnaire responses. 